\title{
UREĐIVAČKE POLITIKE U FEMINISTIČKIM AKADEMSKIM ČASOPISIMA ${ }^{1}$
}

Ovaj tekst se bavi problemom legitimizacije i diseminacije feminističkog znanja u časopisima. Poseban akcenat stavljen je na uređivačke politike, ulogu i značaj uvodnika u časopisu, osobenosti jezika naučnog rada, kao i na vezu - ili odsustvo veze - između teorije i prakse u feminističkim akademskim časopisima. Ove teme se razmatraju na primeru američkog časopisa Signs: Journal of Women in Culture and Society, koji redovno izlazi već četiri decenije.

Ključne reči: feministički akademski časopisi, uvodnik u časopisu, feministička teorija, žensko iskustvo i aktivizam, Signs: Journal of Women in Culture and Society

1 Tekst je nastao u okviru projekta PATTERNS Lectures, koji realizuju WUS iz Austrije i Fondacija ERSTE, i projekta Knjiženstuo - teorïja i istorïja ženske književnosti na srpskom jeziku do 1915. godine (br. 178029) Ministarstva prosvete, nauke i tehnološkog razvoja Republike Srbije. 


\section{UVOD}

Naučni časopisi su mesto gde se znanje i proizvodi i pohranjuje: pored toga što beleže postojeća saznanja i rezultate naučnog rada u okviru jedne ili više oblasti, naučni časopisi služe i analizi, preispitivanju, utemeljivanju ili odbacivanju određenih ideja i pojmova u konkretnoj oblasti/oblastima. Uz to, oni su sredstvo za diseminaciju znanja.

Feministički akademski/naučni časopisi takođe služe proizvodnji i skladištenju znanja. Njihova je uloga da legitimišu i šire feminističko znanje. Istorijski gledano, feministički časopisi su bili forumi za dijalog i sukob, ali i mobilizacijska snaga, odnosno prostor za okupljanje žena, i muškaraca, oko sličnih ideja i zahteva. ${ }^{2} \mathrm{~S}$ obzirom na to, zanima me veza - ili odsustvo veze - između feminističkih akademskih časopisa i društva, odnosno svakodnevnog ženskog iskustva. Baviću se, dakle, problemima koji proizlaze iz (naizgled) nemogućeg saveza između institucionalizovanog znanja oličenog u naučnoj časopisnoj produkciji i feminizma.

Tema ovog rada je široko postavljena. Skrenuću pažnju na neka pitanja i probleme sa kojima se - gotovo uvek - suočavaju urednice feminističkih akademskih/naučnih časopisa. Razume se, nema jednostavnih odgovora na njih, kao što nema ni jednog ispravnog odgovora. Svaka urednica daje odgovor u svoje ime i u ime redakcije.

Moguće odgovore za potrebe ovog teksta potražila sam u časopisu Signs: Journal of Women in Culture and Society. ${ }^{3}$ Pošto se misija časopisa (cilj, svrha, namera) obično saopštava u uvodniku, analiziraću odabrane uvodnike iz ovog časopisa. Razume se, čak i ta ilustracija biće svedena: osvrnuću se na svega nekoliko uvodnika iz časopisa.

2 Dobar primer predstavlja prvi eksplicitno feministički časopis na angloameričkom govornom području - The Freewoman. A Weekly Feminist Review. Njega su pokrenule Dora Marsden (Dora Marsden) i Meri Gotrop (Mary Gawthorpe), čuvene sifražetkinje, koje su napustile 1911. godine Žensku društvenu i političku uniju (Women's Social and Political Union). Za ovaj časopis bili su karakteristični dijalog i rasprava u vezi sa brojnim ženskim/feminističkim pitanjima: od toga šta čini slobodnu ženu, preko (pre)ispitivanja prihvaćenih modela moralnosti i seksualnosti, opisa društvenih i ekonomskih problema sa kojima se žene svakodnevno suočavaju, do kritičkih priloga u kojima se razmatralo žensko stvaralaštvo, kao i reprezentacije žena u umetnosti i književnosti. Rasprave su se iz časopisa prenele u Kružok za diskusiju (The Freewoman Discussion Circle), koji je osnovan s idejom da se zainteresovana publika okuplja, sluša predavanje u grupi, te potom diskutuje. Časopis se gasi već 1912. Svi brojevi su digitalizovani i dostupni na internet stranici Modernist Journals Project: http://www.modjourn.org/render.php?view=mjp object\&id=FreewomanCollection. O uredničkim politikama u ovom časopisu vidi: Ana Kolarić, Rod, modernost i emancipacija. Uredničke politike u časopisima Žena (1911-1914) $i$ The Freewoman (1911-1912) (Beograd: Fabrika knjiga 2017).

3 Vidi: http://signsjournal.org/ 
Četiri decenije redovnog izlaženja Signs-a, kao i njegova čvrsta pozicija na sceni feminističke naučne periodike, dobar su razlog da se iskustva njegovih urednica ozbiljno uzmu u obzir. Zaključci do kojih su one došle mogu biti od koristi u raspravi o domaćim feminističkim akademskim časopisima. ${ }^{4}$

Konačno, treba napomenuti da namera ovog rada nije da idealizuje i romantizuje uspeh Signs-a. Uslovi u kojima on nastaje i opstaje praktično su neuporedivi sa uslovima u kojima se pojavljuju domaći feministički časopisi. Iz te kontekstualno uslovljene razlike proizlaze nejednaki odnosi moći (centar $v$ s. poluperiferija) i njima određena proizvodnja, kao i vidljivost, feminističkog znanja.

Na nekoliko pitanja tražim odgovor u ovom radu:

1. Šta je akademski časopis (cilj/svrha, sadržaj, jezik, publika)?

2. U kakvom su odnosu termin "feminizam" i "akademski časopis" u sintagmi feministički akademski časopis? Drugim rečima, kakva je veza između teorije (znanje, nauka) i prakse (aktivizam, empirija, iskustvo)? Da li se ekspertkinje obraćaju i feministkinjama i "običnim" ženama koje su izvan univerziteta? Da li institucionalizovani oblici feminističkog znanja mogu biti okidači za društvene promene?

3. Da li je i na koji način digitalno doba uticalo na izgled i život feminističkih akademskih časopisa? Da li internet može da bude saveznik tim časopisima u širenju feminističkih ideja i znanja?

\section{ŠTA JE AKADEMSKI ČASOPIS?}

Akademski ili naučni časopis objavljuje tekstove koje potpisuju eksperti, ima recenzente, i najčešće je neprofitan. Njegov je cilj da objavljuje i širi znanje iz jedne ili, nešto ređe, više naučnih oblasti. Opisaću i razmotriti navedene elemente naučnog časopisa. Posebno ću se zadržati na procesu recenziranja jer se on može videti kao distinktivno obeležje naučnog čaospisa. Kada je reč o feminističkoj časopisnoj produkciji, recenziranje se pokazuje kao posebno osetljivo mesto. Prvo, gotovo u svakoj sredini, postoje časopisi koji objavljuju (i) teorijske i kritičke tekstove, ali

4 Autorke koje su se bavile analizom konkretnih časopisa u tekstovima u ovom zborniku posvetile su pažnju uredničkim politikama i, posledično, uvodnicima. O aktivizmu je bilo najviše reči u tekstu Stanislave Barać o Feminističkim sveskama, te u tekstovima Jelene Milinković i Jelene Lalatović o ProFemini. Iako su oba časopisa proizvodila feminističko znanje, oni nisu bili naučni časopisi u strogom smislu te reči. Nekih konkretnih posledica nastojanja da se bude naučni časopis dotakla se Katarina Lončarević u tekstu o Ženskim studijama i, pre svega, Generu, takođe u ovom zborniku. Recimo, feministički naučni časopis, ako se drži zadatih propisa i zahteva, ne može da objavljuje prevode, književne priloge i feminističke eseje bez naučnog aparata. 
nisu klasifikovani i kategorizovani kao naučni zato što ili nisu pokušali ili nisu uspeli da ispune uslove zadate različitim zakonskim aktima/ pravilnicima o tome šta je naučni časopis. Drugo, specifično ekspertsko vrednovanje znanja stoji u delimičnoj opoziciji spram nastojanja feministkinja u Americi u 70-im i 80-im godina 20. veka, a u domaćem kontekstu u 90-im godina, da legitimišu nova, drugačija znanja bazirana na ženskom iskustvu. Štaviše, takva znanja se često saopštavaju kroz manje rigidne naučne forme, poput feminističkog eseja. Sva je prilika da jedan takav esej danas ne bi uspešno prošao proces recenziranja. ${ }^{5}$

\section{Disciplinarnost vs. interdisciplinarnost}

Naučni časopisi uglavnom imaju stabilnu strukturu, zasnovanu na nekoliko standardnih tipova tekstova. U časopisu obično ima najviše originalnih naučnih radova. Potom, mnogi časopisi objavljuju i pregledne radove (tekstove o određenom problemu ili stanju discipline, na osnovu postojeće stručne literature). Konačno, naučna kritika i prikazi stručnih knjiga takođe imaju mesto u naučnim časopisima. Neki časopisi ce imati i dodatne rubrike, poput intervjua ili bibliografija. Radovi koji se objavljuju u akademskim časopisima imaju naučni aparat: apstrakt, ključne reči, rezime, fusnote, spisak primarne i sekundarne literature. Časopisi se obično bave jednom oblašću/disciplinom (sociologijom, književnošću, psihologijom...). Feministički akademski časopisi, naprotiv, uglavnom su interdisciplinarni (odnosno, multi- i transdisciplinarni). To, naravno, ima veze sa tim što su Ženske/Rodne studije inherentno interdisciplinarne. ${ }^{6}$ Međutim, interdisciplinarnost lako može da dovede do problema u kategorizaciji pojedinih feminističkih časopisa (u koju oblast spada određeni časopis?) ${ }^{7}$ i pronalaženju dovoljnog broja

5 Recimo, neki od eseja koji su objavljeni u ProFemini i Ženskim studijama teorijski i tematski ne zaostaju za onim što se danas smatra naučnim radom. No, nisu imali aparat koji podrazumeva naučni rad (apstrakt, ključne reči, rezime...) niti su bili recenzirani. Takvi primeri svedoče o činjenici da se neki rad (ne) klasifikuje kao naučni, pre svega, iz formalnih razloga. Sadržina je u drugom planu ili sasvim zanemarena.

6 Jasmina Lukić opisuje ženske/rodne studije kao "interdisciplinarnu disciplinu”. Vidi: "Ženske/rodne studije i problemi disciplinizacije: uloga časopisa” u ovom zborniku.

7 Katarina Lončarević daje dobar primer: iako je časopis Genero interdisciplinarni časopis unutar polja društveno-humanističkih nauka, Ministarstvo nauke ga je stavilo u kategoriju "pravo i politikologija”, verovatno zato što je glavni izdavač časopisa Fakultet za političke nauke. Drugim rečima, sadržaj časopisa nije uzet u obzir pri kategorizaciji. Vidi: "Stvaranje prostora za feminističku teoriju u naučnoj periodici u Srbiji: časopisi Ženske studije i Genero”, u ovom zborniku. 
recenzenata kompetentnih za više oblasti ili obrazovanih u polju Ženskih/Rodnih studija. ${ }^{8}$

\section{Proces recenziranja}

U izboru radova koje će objaviti naučni časopis mora da se osloni na sud recenzenata. Urednica/urednik/urednici obično izaberu one tekstove koje žele da objave i koje, stoga, šalju na recenziranje. Dakle, neće svi pristigli tekstovi biti uvek recenzirani, neki mogu biti odmah isključeni iz nekog razloga. Recenzenti su eksperti u oblasti kojoj pripada tema teksta koji treba da ocene. Formalno, postupak recenziranja (peer review) može imati tri različita vida: 1) "slepa" recenzija (single blind peer review): recenzenti znaju identitet autora (ime i afilijaciju), dok obrnuto ne važi; 2) "dvostruko slepa" recenzija (double-blind peer review): i recenzenti i autor/i su anonimni; 3) "otvorena" recenzija (open peer review): i recenzenti i autor/i su potpisani. Svaki od navedenih načina vrednovanja naučnog rada ima svoje prednosti i mane. ${ }^{9}$

U idealnom slučaju, kredibilitet recenzenata treba da bude garancija kvaliteta rada koji vrednuju. Međutim, problematična je već sama ideja o "idealnom slučaju”. Šta tačno znači biti objektivan, nepristrasan ili neutralan u čitanju i ocenjivanju nečijeg rada? Da li je znanje ikada neutralno? Generacije feministkinja posvetile su brojne radove navedenim pitanjima da bi utvrdile da znanje nije neutralno, ono je uvek rodno, klasno, rasno... obeleženo. To se odnosi kako na "tvrde" tako i na "meke" nauke, dakle, i na humanistiku. U analizi društva, baš kao i u analizi kulture, nastupamo sa određenih teorijskih/poli-

8 Jasmina Lukić, glavna urednica prvih 13 od ukupno 15 brojeva časopisa Ženske studije, feminističkog časopisa koji je bio zamišljen kao naučni časopis, kaže da časopis nije imao anonimno recenziranje jer praktično nije bilo dovoljno osoba da rade recenzije tekstova u oblasti ženskih/rodnih studija. Vidi u ovom zborniku: "Ženske/rodne studije i problemi disciplinizacije: uloga časopisa”. Pored toga, Ženske studije su bile fokusirane na prevođenje feminističke teorije na naš jezik. Recenziranje se odnosi samo na originalne naučne radove. Kao što znamo, prevodi nisu deo naučnih časopisa danas. To implicira da je znanje u časopisima namenjeno isključivo ekspertima koji poznaju strane jezike.

9 Više o procesu recenziranja, različitim pristupima u okviru samog procesa, te prednostima i ograničenjima svakog od njih: https://www.elsevier.com/reviewers/whatis-peer-review; https://authorservices.wiley.com/Reviewers/journal-reviewers/ what-is-peer-review/types-of-peer-review.html. Vidi i: https://www.theguardian. com/science/2011/sep/o5/publish-perish-peer-review-science. U domaćoj naučnoj zajednici, uobičajena je "dvostruko slepa” recenzija. Naravno, imajući u vidu da se radi o relativno maloj naučnoj zajednici, anonimnost je ipak upitna. 
tičkih/ideoloških stanovišta. Isto tako, kada ocenjujemo tuđe analize, činimo to iz pozicije sopstvenih teorijskih/političkih/ideoloških znanja i uverenja. Naše analize i tumačenja uvek su u određenoj meri - subjektivni. Ovde se valja podsetiti feminističke standpoint teorije prema kojoj je svako znanje društveno određeno i utemeljeno, pa se samim tim dolazi do raskoraka između perspektive neke marginalizovane grupe, s jedne strane, i dominantne grupe, s druge. Dok je perspektiva prve grupe obično izostavljena iz proizvodnje i transmisije takozvanog "legitimnog znanja”, perspektiva potonje obično se nameće kao objektivno, neutralno znanje koje je obavezujuće za sve pripadnike jedne zajednice. ${ }^{10}$

Upečatljiv primer za uticaj ličnih predrasuda na vrednovanje naučnog rada nudi Anđela Kokren (Angela Cochran) kada govori o seksizmu u procesu recenziranja. Naime, jedan recenzent je predložio dvema autorkama da u pisanje nove verzije svog rada uključe bar jednog muškarca kako bi izbegle "ideološki obojene pretpostavke" $\mathrm{u}$ istraživanju. ${ }^{11} \mathrm{Iz}$ ugla ovog primera, Kokren pravi osnovnu razliku između dopustive i poželjne tvrdnje da je neki tekst loš zbog metodologije ili rezultata i nedopustive tvrdnje da je loš zbog pola autorke/ autorki, to jest autora teksta. U vezi sa tim, ona podseća i na važnu ulogu urednika i redakcije u procesu recenziranja: autorke i autori ne bi smeli da budu prepušteni na milost i nemilost neprofesionalnim ili zlonamernim recenzentima. Istovremeno, Kokren se zalaže za "dvostruko slepu" ili, pak, "otvorenu" recenziju, kako bi se izbegle situacije u kojima recenzenti zloupotrebljavaju informacije koje imaju o autorkama/autorima teksta.

Konačno, recenzenti (zajedno sa urednicama i urednicima časopisa) predstavljaju sud stručne javnosti i garantuju da je odobreni tekst vredan čitanja, bilo zbog tematske inovativnosti, metodološke doslednosti, ili relevantnosti za datu naučnu oblast (ovo su sve standardna polja za popunjavanje u recenzentskom listiću). Pošto većina časopisa objavljuje spisak recenzenata na godišnjem nivou ili u svakom broju, to jest, njihova imena se daju na uvid javnosti, recenzenti svojim imenima i titulama garantuju relevantnost časopisa. Pitanje je da li se, na koji način i u kojoj meri sami naučni radovi stavljaju pred sud šire javnosti?

10 Koristan pregled ključnih problema u feminističkoj epistemologiji daje Katarina Lončarević u tekstu "Feministička epistemologija: Nastanak, razvoj i ključni problemi”, u Godišnjak Fakulteta političkih nauka, br. 7, jun 2012, 41-59.

11 Angela Cochran, "Sexism in Peer Review", The Scholarly Kitchen (May 7, 2015), https://scholarlykitchen.sspnet.org/2015/05/o7/sexism-in-peer-review/. 


\section{Diseminacija znanja, stručni jezik, neprofitnost}

Kada je reč o širenju znanja, treba se pitati: kome se ono nudi? Odgovor nije težak: znanje u naučnim časopisma namenjeno je, pre svega, kolegama ekspertima. Akademski časopisi na prvom mestu predstavljaju platformu za razmenu znanja i diskusiju među kolegama unutar jedne ili više disciplina. Međutim, čak i ova vrlo ograničena funkcija naučnih časopisa postaje sumnjiva ako uzmemo u obzir nekoliko problema: hiperprodukciju naučnih radova i njihovu realnu čitanost (kako i kada sve to pročitati?), vidljivost/dostupnost naučnih časopisa tj. članaka (gde pratiti šta se sve objavljuje?), kao i odnose moći među kolegama i posledičan izostanak rasprave (da li je "zameranje" postalo sinonim za "raspravu“?). Dalje, jezik naučnih radova jeste stručni jezik. Taj jezik i radovi njime pisani nisu (lako) razumljivi i dostupni takozvanim običnim čitaocima, odnosno široj čitalačkoj publici. To je još jedan razlog zašto naučne časopise čitaju - praktično isključivo - eksperti (i to oni zainteresovani samo za određenu disciplinu ili temu) i, potencijalno, njihovi studenti.

Danas se vrlo često može čuti da je institucionalizacija Ženskih studija dovela do njihove depolitizacije, jer su se feministkinje koje rade na univerzitetu odvojile od društvene realnosti, kako zbog često hermetičnog i teškog teorijskog jezika u njihovim tekstovima, tako i zbog privilegovane pozicije. Otuda ne čudi da se mnoge feministkinje u akademiji, pa tako i urednice feminističkih naučnih časopisa, povremeno pitaju kako o relevantnosti feminističkog znanja za širu zajednicu (kome se obraćamo, na koji način, s kojim razlozima?) tako i o sprezi teorije (znanja) i prakse (aktivizma). U tekstu o paradoksima feminističkog akademskog časopisa, jedna od bivših urednica časopisa Signs, privržena feminističkom aktivističkom i političkom projektu, kaže da su u vreme njenog uredničkog mandata za tematski broj časopisa posvećen feminističkoj teoriji i praksi pristigli teorijski tekstovi koji su ignorisali praksu, kao i teorijski neosvešćeni tekstovi o praksi, što je ukazalo na to da se ova dva polja delovanja retko presecaju. ${ }^{12}$

Objavljivanje naučnih časopisa, barem u Srbiji, ne zavisi od njihovog uspeha na tržištu. To znači da ovi časopisi mogu da izlaze čak i ako nemaju nijednog čitaoca. Činjenica da većina časopisa nije profitna/komercijalna, predstavlja istovremeno i dobru i lošu vest. S jedne strane, objavljivanje akademskih časopisa nije uslovljeno njihovim uspehom na tržištu, kao što i ne treba da bude: znanje bi trebalo da

12 Rut-Ellen Boetcher Joeres, "The Paradox of a Feminist Academic Journal”, u The Yale University Journal of Criticism, Vol. 10, No. 2, 1997, 439-443. 
se akumulira u jednoj zajednici čak i kada ne postoji šira publika za određene oblike znanja. S druge strane, hiperprodukcija naučnih radova rezultat je nerealnih, često tehnokratskih zahteva za napredovanje u karijeri. Ako ti i takvi zahtevi postanu osnovni, pa i jedini razlog za objavljivanje naučnih radova, onda se zaista može postaviti pitanje o opravdanosti i relevantnosti određenih znanja, ali i određenog tipa časopisne produkcije.

O dobrim i lošim stranama uređivanja jednog feminističkog časopisa piše i Liza Meklohlin (Lisa McLaughlin). Posle šesnaest godina najpre samostalnog a potom i zajedničkog uređivanja časopisa Feminist Media Studies, ona govori o svom uredničkom iskustvu. ${ }^{13}$ Zadržaću se na njenim uvidima o kategorizaciji časopisa. Meklohlin opisuje kako je izgledalo osnivanje časopisa (sastavljanje redakcije, pozivanje saradnica i saradnika, odnosi sa izdavačem...) i naglašava poteškoće u traženju autora/saradnika i recenzenata za jedan sasvim nov časopis: drugim rečima, nije bilo jednostavno ubediti poznat(ij)a imena da pišu ili recenziraju za nov i nepoznat časopis i tako mu daju legitimitet. Činjenica da časopis Feminist Media Studies nije na listi Tomson Rojters (Thomson Reuters) i da nema "faktor uticaja" (impact factor) uticala je na to da u redakciju stiže manji broj tekstova. Liza Meklohlin to objašnjava: u nekim zemljama obrazovni sistem, odnosno Ministarstvo obrazovanja (ili druge slične institucije), zahteva od naučnih radnika da objavljuju isključivo u "odobrenim" časopisima, to jest u onim časopisima koji se nalaze na određenim listama, poput liste Tomson Rojters. Autorka smatra da su takve liste iz brojnih razloga problematične, kao i da su naučni časopisi, pa tako i feministički, korporatizovani pristankom da uđu na razne liste, odnosno da su izgubili iz vida ideju "opšteg dobra" onog trenutka kada su pristali na nadmetanje, ocenjivanje, faktore uticaja, naplatu pristupa časopisu i slično. Pitanja kategorizacije, vrednovanja, kao i sve zloupotrebe povezane sa tim, a ne sa strukom, učinila su da joj bude drago što više nije na mestu urednice.

Kao suprotan primer, treba pomenuti časopis Feminist Studies, osnovan 1972. godine. U odeljku "O nama", na internet stranici ovog časopisa, piše da pored istraživačkih radova, odnosno teorijskih i kritičkih tekstova, časopis u istoj meri objavljuje i "umetničke, kreativne i aktivističke" priloge, to jest umetnički esej, poeziju i prozu, foto-

13 Lisa McLaughlin, "Feminist Journal Editing: Does This Job Include Benefits", $\mathrm{u}$ Ada: A Journal of Gender, New Media, and Technology, Issue no. 4, https:// adanewmedia.org/2014/o4/issue4-mclaughlin/. 
esej, komentare na relevantne teme. ${ }^{14}$ Naglašava se da se uredništvo sastoji od stručnjaka iz brojnih disciplina, što omogućava vrednovanje tekstova kako iz jedne discipline tako i onih koji neguju interdisciplinarni pristup. U ovom odeljku se navode tri razloga zašto faktor uticaja nije relevantan indikator značaja i reputacije jednog feminističkog časopisa. ${ }^{15}$ Prvo, faktori uticaja se računaju na osnovu citatnosti u poslednja tri godišta časopisa. Dok je recentnost možda važna za prirodne nauke, ona je znatno manje bitna za humanistiku. Drugo, Feminist Studies ne objavljuje nijedan univerzitet (ovaj časopis je samizdat, a sedište mu je na Odseku za ženske studije, pri Univerzitetu u Merilendu). To znači da u ovom časopisu nema razloga za "prinudno" citiranje da bi se obezbedio rast faktora uticaja određenog izdavača. Treće, pošto Feminist Studies objavljuje i nenaučne žanrove, ne može da dobije faktor uticaja koji je rezervisan isključivo za naučne časopise. Uprkos svemu tome, pozicija ovog časopisa je takva da na godišnjem nivou prihvati i objavi svega oko 8 posto od ukupnog broja pristiglih tekstova.

\section{AKADEMSIKI FEMINIZAM I FEMINISTIČKI AKTIVIZAM}

Ispitaću vezu između termina "feminizam" i "akademski časopis" u sintagmi feministički akademski časopis na primeru časopisa Signs. Časopis ${ }^{16}$ je osnovan 1975. i izlazi četiri puta godišnje. Od osnivanja do danas izdaje ga Univerzitet u Čikagu (University of Chicago Press). Signs je jedan od prvih feminističkih (akademskih) časopisa koji su osnovani ranih sedamdesetih godina, odnosno u vreme kada Ženske studije formalno postaju deo visokog obrazovanja. Urednica, odnosno urednice časopisa menjaju se na svakih pet godina; tom prilikom časopis menja sedište, to jest seli se na univerzitet na kom radi glavna urednica. Nova urednica (urednice) piše uvodnik pri preuzimanju časopisa i izlaže sopstvenu uredničku politiku. Neke urednice napisale su uvodnike i kada su napuštale to mesto posle pet godina. Časopis je pokrenula Ketrin R. Stimpson (Catharine R. Stimpson), tada profesorka književnosti na koledžu Barnard (Barnard College). Međutim, inicijativa za pokretanje časopisa došla je od Džin Seks (Jean Sacks),

14 Vidi: http://www.feministstudies.org/aboutfs/history.html.

15 Vidi: Ibid.

16 O časopisu: http://signsjournal.org/about-signs/history/. Pored toga, zanimljiva je stranica koja je posvećena četrdesetogodišnjici izlaženja časopisa, gde su objavljene analize (od kvantitivne do kvalitativne) tema i "teorijskih zaokreta”, komentari urednica i saradnica, itd. Vidi o tome: http://signsat40.signsjournal.org/. 
koja je u to vreme bila menadžerka odeljenja za časopise pri Čikago Pres-u. Ona je sarađivala sa časopisom Signs sve do odlaska u penziju 1984. godine.

Ketrin Stimpson i druge urednice istakle su u uvodniku prvog broja da je svrha časopisa da nešto učini živim, da nešto podstakne. ${ }^{17}$ Časopis ima najmanje dva cilja: Signs treba da objavljuje nova znanja o ženama iz Amerike i drugih zemalja, te da bude interdisciplinaran. ${ }^{18}$ Zahtev za interdisciplinarnošću pojavio se dakle još 1975, a proistekao je iz saznanja da "istina može biti jednostavna, ali da nikada nije monolitna". ${ }^{19}$ Signs će objavljivati različita, često suprotstavljena stanovišta, pišu urednice. ${ }^{20} \mathrm{U}$ zaključku, urednice prave čvrstu vezu između feminističkog naučnog časopisa, kakav je Signs, i intelektualnih i društvenih pokreta, pre svega iz 60-ih godina, bez kojih on ne bi bio moguć.

U tom prvom uvodniku navode se rubrike od kojih će se Signs sastojati: kratak uvodnik, naučni članci, nekoliko preglednih eseja (eseji o postojećim proučavanjima ženskog iskustva /study of women/ u različitim disciplinama), prikazi knjiga, izveštaji/revizije, pisma, arhive (razna dokumenta od pre 1950. godine, ali marginalizovana ili “izgubljena”). Prvi i četvrti broj jednog godišta časopisa biće tematski. Uz neke izmene (na primer, dodavanje novih rubrika), osnovni raspored glavnih rubrika zadržan je do danas.

Ciljevi i nastojanja istaknuti u prvom uvodniku - pre svih, interdisciplinarnost i diverzitet - prisutni su već 40 godina u časopisu, uprkos brojnim i ponekad krupnim promenama kako u nauci tako i u svetu. Svi uvodnici u časopisu Signs imaju određene sličnosti: nove urednice obično odaju priznanje svojim prethodnicama, ukazuju na dobre tradicije časopisa, te potom navode potencijalne novine u sopstvenoj uređivačkoj politici. Osvrnuću se nešto detaljnije na uvodnike iz prve polovine devedesetih godina 20. veka, kao i na poslednji inauguracioni uvodnik iz 2015, jer su u njima eksplicitno pokrenuta pitanja u vezi sa feminističkim delovanjem unutar i izvan univerziteta.

Rut-Elen Betčer Hjures (Ruth-Ellen Boetcher Joeres) i Barbara Lezlet (Barbara Laslett), obe sa Univerziteta u Minesoti, preuzele su časopis 1990. godine. U prvom uvodniku, iz 1991, urednice kažu da je pokretanje rubrike pod nazivom "Forum" jedna od novina u njihovom

17 Catherine R. Stimpson, Joan N. Burstyn, Donna C. Stanton, Sandra M. Whisler, "Editorial", u Signs, Vol. 1, No. 1 (Autumn, 1975), v.

18 Ibid.

19 Ibid., vi.

20 Ibid. 
uređivanju časopisa. Ta rubrika ima dvostruki cilj: prvo, treba da služi kao mesto rasprave o relevantnim pitanjima u vezi sa kojima se mišljenja često razlikuju; drugo, treba da bude prostor za diskusiju o svim javnim i programskim problemima koji utiču na živote žena, odnosno da se bavi različitim strategijama i javnim politikama. ${ }^{21}$ Šta je, dakle, osnovni cilj "Foruma“? Da se časopis Signs iznova poveže sa aktivističkim problemima ženskog pokreta. Ti problemi su predstavljali osnovni razlog za osnivanje ženskih/feminističkih studija. ${ }^{22}$ Drugim rečima, smatra se da aktivizam i naučni rad nisu suprotstavljeni niti bi trebalo da se isključuju; naprotiv, te dve oblasti delovanja moraju biti povezane. Teško je pratiti aktuelna pitanja u časopisu koji izlazi četiri puta godišnje, pa zato urednice akcenat stavljaju na strategije i javne politike. Betčer Hjures i Lezlet insistiraju da je ideja o rodnoj neutralnosti, kakva se može čuti u akademskom okruženju, suštinski depolitizujuća. ${ }^{23}$

U časopisu Signs uvodnik se nalazi u svakom broju. Naime, pored "programskih" uvodnika novih urednica koji se pojavljuju na svakih pet godina, urednice pišu uvodnike i za svaki broj časopisa. U jednom broju iz 1992. Betčer Hjures je objavila uvodnik "O pisanju feminističkih akademskih tekstova”. Bio je to provokativni tekst koji je postavio neka suštinska, nimalo prijatna pitanja o vezi između feministkinja zaposlenih na univerzitetu i društva. Na samom početku, Betčer Hjures pita:

Koliko ličimo na akademski establišment u kome smo se obrazovale, protiv kog smo se često bunile, i u koji smo sada u velikoj meri uronjene? Koje su temeljne tendencije - posvećenost komunikaciji, dostupnosti/prijemčivosti, potrebi da privučemo i uverimo čitalačku publiku - vidljive u načinu na koji pišemo? Kako definišemo našu čitalačku publiku? Do koga želimo da dopremo? Da li smo usko ili široko orijentisane u našim obraćanjima? Kada definišemo sebe kao feministkinje s univerziteta, da li jednako naglašavamo reč "univerzitet" i reč "feministkinja" ili na jednu od njih stavljamo jači naglasak? ${ }^{24}$

Dakle, autorka (se) otvoreno pita: ko nas čita i ko nas razume? U temelju njenog pitanja nalazi se važna dilema o vezi između akadem-

21 Ruth-Ellen Boetcher Joeres, Barbara Laslett, "Editorial: Looking Backward, Moving Forward”, u Signs, Vol. 16, No. 3 (Spring, 1991), 436.

22 Ibid.

23 Ibid., 438.

24 Ruth-Ellen Boetcher Joeres, "Editorial: On Writing Feminist Academic Prose”, u Signs, Vol. 17, No. 4 (Summer, 1992), 701. 
skog feminizma i feminističkog aktivizma. Betčer Hjures smatra da znanje koje se proizvodi u časopisu Signs treba da bude relevantno za žene uopšte. Ako je tako, onda jezik časopisa treba da bude jasan i precizan. Kao što znamo, u naučnim časopisima to često nije tako. S tim u vezi, ona govori o jednoj od posledica institucionalizacije Ženskih studija: jezik koji feministkinje zaposlene na univerzitetu koriste u tekstovima često se oslanja na takozvanu visoku teoriju, složen je i ponekad nerazumljiv, te nužno odbija čitateljke i čitatelje. Zato Betčer Hjures zagovara povratak žanru (feminističkog) eseja. Takav esej obično ima u vidu i pojedinca i grupu, te koristi jednostavan i razumljiv jezik. Dovoljno je podsetiti se eseja kakve pišu, recimo, bel huks (bell hooks) i Edrijan Rič (Adrienne Rich), poput onih u knjigama Feminizam je za sve. Strastvena politika, odnosno O lažima, tajnama i šutnji. Odabrana proza 1966-1978. Razume se, Betčer Hjures i dalje veruje da su jednom naučnom časopisu neophodni feministički naučni radovi, koji se često bave složenim teorijskim pitanjima. Ali, ona smatra da čak i tada forma i jezik tekstova mogu biti pristupačniji i jednostavniji: "To ne znači da treba da pišemo pojednostavljeno, već da tokom pisanja treba da imamo na umu našu želju da komuniciramo". ${ }^{25}$

Betčer Hjures i Lezlet napisale su i "oproštajni” uvodnik posle pet godina uređivanja. Tekst je objavljen u proleće 1995. Autorke sumiraju sve što su naučile o teoriji i praksi uređivanja jednog američkog feminističkog naučnog časopisa u prvoj polovini 90-ih. Jedna od njihovih osnovnih tema jeste dostupnost tekstova koji su objavljeni u Signs-u, kako jezička tako i idejna. Urednice podsećaju na snažne reakcije koje je izazvao raniji uvodnik o pisanju feminističkih akademskih tekstova: javile su im se feministkinje akademske radnice (među njima je bila i jedna od urednica Signs-a) da kažu da taj uvodnik zagovara jednu vrstu antiteorijskog mišljenja i antiintelektualizma. Kada je reč o jeziku i njegovoj upotrebi, odlazeće urednice primećuju da ipak nisu pronašle alat pomoću kog bi razgradile patrijarhalnu univerzitetsku kuću. ${ }^{26} \mathrm{U}$ zaključku, njih dve ponavljaju da je praksa satkana od teorije, baš kao što je feministička teorija utemeljena u praksi. ${ }^{27} \mathrm{Na}$ pitanje o tome da li akademski feminizam može biti politički i aktivistički, one impliciraju da može i, u isto vreme, upozoravaju da u svakoj analizi i debati treba uzeti u obzir institucionalni

25 Ibid., 704.

26 Barbara Laslett, Ruth-Ellen B. Joeres, "Editorial: Looking Backward, Moving Forward: Five Years Later”, u Signs, Vol. 20, No. 3 (Spring, 1995), 513.

27 Ibid., 514. 
okvir, unutar kog časopis izlazi a saradnice rade, i njime nametnuta ograničenja. ${ }^{28}$ Međutim, iz njihovog oproštajnog obraćanja, kao i iz uvodnika i drugih tekstova o uređivanju koje je pisala Betčer Hjures, jasno se vidi da akademski feminizam ima učinka najviše, a ponekad i isključivo, unutar akademije.

\section{FEMINISTIČKI AKADEMSKI ČASOPISI, INTERNET I JAVNOST}

O odnosu između akademskog feminizma i društvene stvarnosti, kao i o prisustvu feminističkog znanja u javnosti, još eksplicitnije piše Suzana Danuta Volters (Suzanna Danuta Walters) u uvodniku iz 2015. godine. Nova urednica se zahvaljuje svojim prethodnicama i posebno ističe pojedine doprinose urednice koja joj je neposredno prethodila. Reč je o Meri Hoksvort (Mary Hawkesworth) sa Univerziteta Ratgers, koja je uspostavila nagradu "Ketrin Stimson" za izuzetan feministički rad, pokrenula internet izdanja, inicirala pokretanje elektronskog časopisa pod nazivom Films for the Feminist Classroom, koji je sastavni deo internet stranice časopisa Signs. ${ }^{29}$

Danuta Volters potom skreće pažnju na ulogu i uticaj digitalnog doba u svim oblastima: šta uopšte znači misliti i raditi feministički u vreme kada je sve online? Baš zato što je danas sve dostupno na mreži ova urednica smatra da redakcija Signs-a treba da obezbedi "interaktivno digitalno prisustvo" časopisa. To nas vodi ka trećem pitanju s početka ovog teksta: Da li je i na koji način digitalno doba uticalo na izgled i život feminističkih akademskih časopisa? Da li internet može biti saveznik feminističkim naučnim časopisima u širenju feminističkog znanja?

Suzana Danuta Volters opisuje inovacije u radu i izgledu časopisa Signs posle 2015. godine. Izdvojiću ovde projekat "Feministkinje javne intelektualke" (Signs Feminist Public Intellectuals Project), jedan od rezultata nastojanja nove urednice da časopis aktivno učestvuje u kreiranju kritičke mase javnih intelektualaca koji nastupaju kao feministkinje i feministi.

Opis tog projekta nalazi se na internet stranici časopisa:

28 Ibid., 514. Slične zaključke Rut-Elen Betčer Hjures iznosi i na drugim mestima. Vidi, na primer: Rut-Ellen Boetcher Joeres, "The Paradox of a Feminist Academic Journal".

29 "Prečica" koji vodi na ovaj časopis nalazi se na internet stranici časopisa Signs: http://signsjournal.org/features/films-for-the-feminist-classroom/. 
U skladu sa duhom misije časopisa Signs da utiče na stvari u svetu, projekat Feministkinje javne intelektualke želi da poveže feminističke teoretizacije sa gorućim političkim i društvenim pitanjima pomoću tri online inicijative s otvorenim pristupom: Kratki osvrti, Tendencije, i Pitajte feministkinju. S obzirom na razuđenost feminističkog aktivizma, kao i zbog negativne upotrebe etikete "feministkinja" odnosno "feministički", projekat Feministkinje javne intelektualke će nastojati da iznova osmisli ulogu koju časopis može da ima u društvu. Ovaj projekat sa višestrukom namenom pokrenuće razgovor između feministkinja javnih intelektualki i ekspertkinja, aktivistkinja i naučnica, sa ciljem da podstakne razgovor, debatu i kritički feministički diskurs..$^{30}$

Rubrika "Tendencije" predstavlja svojevrsni pojmovnik feminističke teorije u okviru kog se definiše neki od ključnih pojmova, daje njegov istorijat i nudi problematizacija. "Kratki osvrti" jeste rubrika fokusirana na društvena i politička pitanja. Ona se obično sastoji od nekoliko kraćih tekstova, odnosno reakcija na knjigu od šireg značaja. Recimo, u jesenjem izdanju Signs-a iz 2017. objavljuju se reakcije ${ }^{31}$ na knjigu We Were Feminists Once Endi Cajsler (Andi Zeisler), objavljenu 2016, kao i odgovor autorke knjige, urednice feminističkog portala Bitch Media ${ }^{32}$ i časopisa Bitch: Feminist Response to Pop Culture. U rubrici "Pitajte feministkinju" objavljuju se intervjui s poznatim feministkinjama na aktuelnu temu od opšte važnosti. Sve tri rubrike nalaze se i u štampanom izdanju časopisa i na sajtu časopisa (razume se, audio i video materijali su dostupni isključivo na sajtu časopisa). Danuta Volters naglašava značaj interneta i društvenih mreža, posebno za mlađu generaciju, i vidi ove virtuelne prostore kao potencijalne prostore za delovanje. Po njoj, i časopis i elektronski portal časopisa treba da budu mesto intelektualnog i aktivističkog rada.

\section{ZAKLJUČAK}

Ovde sam razmatrala šta je naučni časopis, potom šta je feministički naučni časopis i koji su sve paradoksi sadržani u toj sintagmi, te kakva je uloga interneta u radu feminističkih naučnih časopisa. Za primer sam uzela Signs, institucionalizovani, ugledni feministički

30 Za više informacija o projektu i pojedinačnim podprojektima, vidi: http://signsjournal.org/feminist-public-intellectuals-project/.

31 Vidi: http://signsjournal.org/zeisler/.

32 Vidi: https://www.bitchmedia.org/. 
naučni časopis. U jednom od uvodnika, Meri Hoksvort daje podatke o broju objavljenih tekstova u časopisu u periodu od pet godina. Naime, između 2005. i 2010. godine u redakciju je stiglo 1607 tekstova iz 80 zemalja. Objavljeno je 210 tekstova, odnosno oko 13 posto od ukupnog broja. Nema spora da je reč o uspešnom naučnom časopisu (dovoljno je pomenuti kontinuitet i redovnost izlaženja, raznovrsnost tema, teorijsku aktuelnost itd.). Baš zato deluje ohrabrujuće što mnoge urednice Signs-a, iz svog zaštićenog akademskog zabrana, postavljaju pitanje o ulozi i odgovornosti feminističkog akademskog časopisa u društvu. Kako smo videli, to pitanje je vodilo nekim konkretnim inicijativama, poput pokretanja projekta "Feministkinje javne intelektualke" ili kreiranja mesta otpora \#Feminist Resistance kao reakcije na stupanje Donalda Trampa (Donald Trump) na mesto predsednika Amerike, odnosno na njegovu zvaničnu politiku. ${ }^{33}$ Čini se da urednice i saradnice časopisa Signs ipak ne zaboravljaju da je feminizam pre svega politički projekat posvećen borbi za bolji položaj žena u društvu, kritici i ukidanju svake nejednakosti i diskriminacije, odnosno postizanju socijalne pravde. U tom smislu, ovaj časopis, baš kao i njegovo prisustvo na mrežama (audio i video materijali na internet stranici časopisa, Facebook, Twitter itd.), mogu se videti kao primer dobrih feminističkih praksi ili barem pokušaja da se bude društveno relevantan.

Načelna pitanja s početka teksta, kao i primeri iz časopisa Signs, mogli bi se koristiti u razmatranju uredničkih politika u feminističkim naučnim časopisima uopšte. Iako uvodnici u časopisima u praksi nisu obavezujući (odnosno, važnije je šta se zaista nalazi u jednom časopisu od onoga što je u uvodniku obećano), njihova simbolična uloga nije zanemarljiva. Prvo, programski uvodnici definišu misiju i nameru časopisa, kao i teorijsko/ideološko stanovište. U izvesnom smislu, uvodnici zahtevaju od urednica da opišu svoje "politike mesta”, ${ }^{34}$ odnosno da preuzmu odgovornost za poziciju s koje govore $(\mathrm{u}$ ovom slučaju, za izbor saradnica i saradnika, izbor tekstova, dominantan pravac u časopisu itd.). Drugo, uvodnici koji se pišu za svaki broj časopisa mogu da posreduju između tekstova i čitalačke publike tako što će objasniti zašto su objavljeni baš ti tekstovi baš tada. Time bi se sprečilo da sadržaj časopisa za čitateljku deluje kao nasumičan niz stručnih tekstova. Ujedno, time se osnažuje urednička figura: u

33 Vidi: http://signsjournal.org/feministresistance/.

34 Adrienne Rich, "Notes toward a Politics of Location (1984)", u Adrienne Rich, Blood, bread, and poetry. Selected prose 1979-1985. (W. W. Norton \& Company, New York, London, 1986), 210-231. 
svakom broju urednica direktno komunicira sa čitateljkama, a u tim obraćanjima praktično oblikuje poželjnu, implicitnu čitateljku, što je jedan aspekt mobilizacijskog potencijala časopisa. Konačno, pitanja s početka teksta, kao i neki odgovori ili inicijative urednica časopisa Signs, primoravaju nas da, bilo kao urednice bilo kao autorke, svaki put iznova promislimo o tome kome se obraćamo svojim tekstovima i s kojim razlozima.

\section{LITERATURA}

Cochran, Angela. "Sexism in Peer Review". U The Scholarly Kitchen, May 7, 2015. https://scholarlykitchen.sspnet.org/2015/05/07/sexism-in-peer-review/.

Joeres, Rut-Ellen Boetcher. "The Paradox of a Feminist Academic Journal”. U The Yale University Journal of Criticism, Vol. 10, No. 2, 1997, 439-443.

Joeres, Ruth-Ellen Boetcher, Barbara Laslett. "Editorial: Looking Backward, Moving Forward”. U Signs, Vol. 16, No. 3 (Spring, 1991), 433-440.

Joeres, Ruth-Ellen Boetcher. "Editorial: On Writing Feminist Academic Prose”. U Signs, Vol. 17, No. 4 (Summer, 1992), 701-704.

Kolarić, Ana. Rod, modernost i emancipacija. Uredničke politike $u$ časopisima Žena (1911-1914) $i$ The Freewoman (1911-1912). Beograd: Fabrika knjiga, 2017.

Lončarević, Katarina. "Stvaranje prostora za feminističku teoriju u naučnoj periodici u Srbiji: časopisi Ženske studije i Genero”. U ovom zborniku.

Lončarević, Katarina. "Feministička epistemologija: Nastanak, razvoj i ključni problemi”. U Godišnjak Fakulteta političkih nauka, br. 7, jun 2012, 41-59.

Laslett, Barbara, Ruth-Ellen B. Joeres. "Editorial: Looking Backward, Moving Forward: Five Years Later”. U Signs, Vol. 20, No. 3 (Spring, 1995), 507-515.

Lukić, Jasmina. "Ženske/rodne studije i problemi disciplinizacije: uloga časopisa”. U ovom zborniku.

McLaughlin, Lisa. "Feminist Journal Editing: Does This Job Include Benefits". U Ada: A Journal of Gender, New Media, and Technology, Issue no. 4, https://adanewmedia.org/2014/04/issue4-mclaughlin/. 
Rich, Adrienne. "Notes toward a Politics of Location (1984)". U Adrienne Rich, Blood, bread, and poetry. Selected prose 1979-1985. W. W. Norton \& Company, New York, London, 1986, 210-231.

Stimpson, Catherine R., Joan N. Burstyn, Donna C. Stanton, Sandra M. Whisler. "Editorial”. U Signs, Vol. 1, No. 1 (Autumn, 1975), v-viii.

\section{INTERNET STRANICE}

http://www.modjourn.org/render.php?view=mjp_object\&id=FreewomanCollection

http://signsjournal.org/

https://www.elsevier.com/reviewers/what-is-peer-review

https://authorservices.wiley.com/Reviewers/journal-reviewers/ what-is-peer-review/types-of-peer-review.html

https://www.theguardian.com/science/2011/sep/o5/publish-perishpeer-review-science

http://www.feministstudies.org/aboutfs/history.html

http://signsjournal.org/about-signs/history/

http://signsjournal.org/features/films-for-the-feminist-classroom/

http://signsjournal.org/feminist-public-intellectuals-project/

ttp://signsjournal.org/zeisler/

https://www.bitchmedia.org/

http://signsjournal.org/feministresistance/

\section{THE POLITICS OF EDITING IN FEMINIST}

\section{ACADEMIC/SCHOLARLY JOURNALS}

This article explores the problems of legitimizing feminist knowledge in journals and, then, the question of disseminating this knowledge. The article focuses on the politics of editing, significance of the editorials, specificities of the scientific/academic language, and relationship between theory and practice in the feminist scholarly journals. The famous American journal Signs: Journal of Women in Culture and Society provides some illustrative examples regarding the raised questions.

Keywords: feminist academic/scholarly journals, editorials, feminist theory, women's experience and activism, Signs: Journal of Women in Culture and Society 